\title{
VARIATION OF ATMOSPHERIC ELECTRIC CONDUCTIVITY CONNECTED WITH WIND
}

M. Takagi, H. Jindo, M. Kanada, and N. Toriyama

Solar-Terrestrial Environment Laboratory, Nagoya University, Toyokawa 442

Abstract. The variation of atmospheric electric conductivity observed at Sakushima in Mikawa Bay was analyzed in connection with the wind velocity and direction. In winter the atmospheric conductivity shows the variation very similar to the wind strength, but in summer there is almost no correlation between them. The difference is mainly related with wind directions characteristic in the respective seasons. The close correlation seen in winter is thought to depend upon the continuance of north-westerly prevailing in this season and the geographical circumstances of observation site concerning the pollution sources.

\section{Introduction}

The wind is a significant element to affect the electrical state in the atmosphere, and its influence on the variations of conductivity, field, or aerosól distributions has been discussed in many papers from various stand points. It has been known for long that the electric conductivity and wind strength in the lower atmosphere sometimes vary in parallel with each other (Ogawa, 1960; Israel, 1970). We noticed it in the early days of atmospheric electricity observation at Sakushima Observatory $\left(34^{\circ} 44^{\prime} \mathrm{N}, 137^{\circ} 03^{\prime} \mathrm{E}\right)$ that there was a close correlation between the atmospheric conductivity and wind velocity in winter but not in summer (Iwata et al., 1975; Morita et al., 1977). The situations of the two parameters repeat regularly every year. This report is concerned with the analysis of conductivity observations at Sakushima in the period of recent two years from August 1988 to July 1990, when we have obtained stable data set for comparatively long period.

2. Observation and results

Observations at Sakushima were made at a station, the south side of which fronts to the sea water with $25 \mathrm{~m}$ distance. The conductivity was measured in a wind-through room at a height of $7 \mathrm{~m}$, and the wind was measured on the roof of the building at $12 \mathrm{~m}$ height above the ground. Routine observations of conductivity were made for positive polarity and the negative one was measured only during some intensified observation periods. The instrument for the conductivity measurement is a Gerdien-type coaxial cylinder. The value of conductivity of positive polarity is registered together with meteorological elements, in every 5 minutes with the aid of micro-computer. Calibration and check of the system was usually made every two weeks. The system was operated continuously and automatically. Instrumental troubles sometimes happened, but in more than $90 \%$ of the analysed period the reliable data were obtained. The data used in analysis are the hourly values, i. e. usually the averages of 12 samplings between 0 and $60 \mathrm{~min}$ every hour.

Figures $1(A)$ and (B) shown first are two typical examples, which represent the variations for 14 days respectively in winter and in summer. 

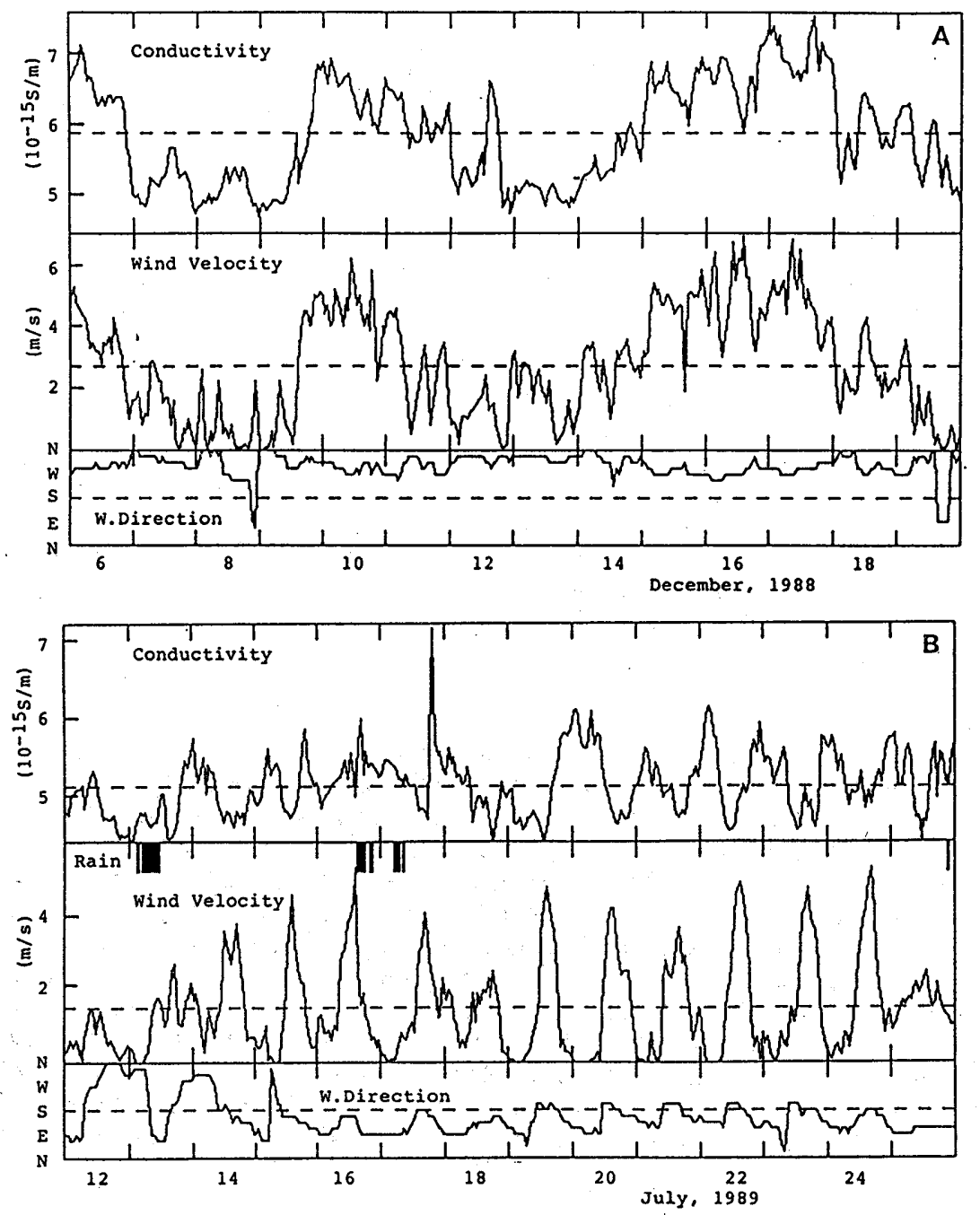

Fig. 1. Variations of positive polar conductivity, wind velocity and direction. A:December 6-19, 1988, B: July 12-25, 1989.

The examples are selected from the period when relatively stable weather continues. In the figures, the positive polar conductivity, wind velocity, and direction are arranged from the top. Black stripes between conductivity and wind velocity in (B) indicate the period of rain. No rain was observed in the period of (A). Horizontal broken lines in conductivity and wind velocity are the respective mean values during the period shown here.

At a first look at Fig. 1(A), parallel variations of the conductivity and wind velocity are obvious for the long variation cycle of 4 to 6 days as well as the short cycle of several hours. There is neither retard nor advance between the two: this is numerically confirmed by calculating cross correlations of them. The direction of wind is almost always in west to north in this season. On the other hand, the variation pattern in summer in Fig. 1 (B) is quite different. The wind is mainly in east to south, and under calm weather conditions a regular daily variation is seen both in 

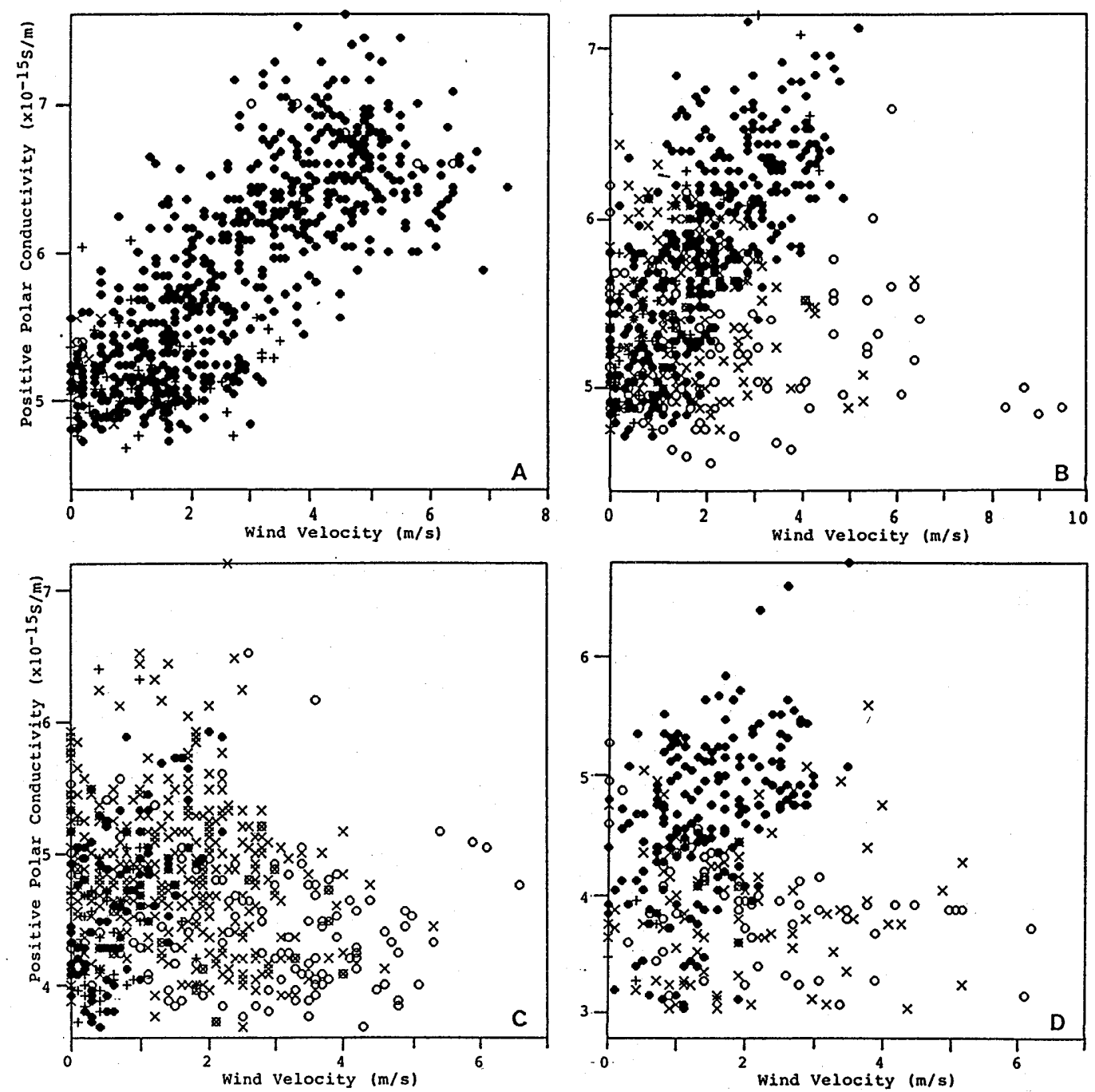

Fig. 2. Correlation between positive polar conductivity and wind velocity. See text for marks.

A:December 1988, B:April 1989, C:July 1989, D:September 1989.

velocity and direction of wind. In the regular pattern the conductivity variation is rather in opposite sense to the wind velocity.

To see more generally these relations, Figs. 2 (A) to (D) show the correlation between the conductivity and the wind velocity, respectively for a month in each season. In the figures different marks are used corresponding to different wind directions. For the sake of convenience, the directions are divided into four $90^{\circ}$ sectors, respectively denoted hereafter as $\mathrm{NE}(+), \mathrm{SE}(x), \mathrm{SW}(0)$, and $\mathrm{NW}(\bullet)$. These correspond to azimuths -11.25-78.75 (N-ENE), 78.75-168.75 (E-SSE), 168.75-258.75 (S-WSW), and 258.75$348.75^{\circ}(W-N N W)$, respectively.

Figure $2(\mathrm{~A})$ represents the typical winter: almost all the time NW wind prevails in this month. It is obvious that the conductivity has a high correlation with the wind velocity. Figure 2(B) applies to transient 
period from winter to summer. NW wind still covers half of all directions. It is notable that the two parameters have a close correlation in NW direction indicated with the mark $(\bullet)$, but not in other directions. Even in summer shown in Fig. $2(\mathrm{C})$, NW wind seems to produce a positive relation to conductivity, while the wind of other directions rather has an inverse relation. Figure 2 (D) is of the transient period from summer to winter, and the characteristics here are very similar to (B).

As described first, the analysis was made for the period of 2 years. Table 1 shows the monthly occurrence percentage of wind directions, divided in four denoted as above, averaged in the two years. The winter type covers half a year from October to March. Table 2 is the result of calculation of correlation coefficient. The characteristics noticed in the variation curves in Figs. $1(\mathrm{~A})$ and (B) are confirmed numerically.

Table 1. Distribution of Wind Direction (\%)

\begin{tabular}{lrrrr}
\hline & NE & SE & SW & NW \\
\hline Jan & 11 & 3 & 3 & 83 \\
Feb & 7 & 9 & 4 & 80 \\
Mar & 9 & 9 & 8 & 74 \\
Apr & 9 & 24 & 14 & 53 \\
May & 10 & 30 & 18 & 42 \\
Jun & 8 & 45 & 19 & 28 \\
Jul & 7 & 56 & 21 & 16 \\
Aug & 6 & 50 & 25 & 19 \\
Sep & 10 & 33 & 17 & 40 \\
Oct & 9 & 10 & 6 & 75 \\
Nov & 8 & 9 & 5 & 78 \\
Dec & 8 & 1 & 1 & 90 \\
& & & & \\
Year & 8 & 23 & 12 & 57 \\
\hline
\end{tabular}

Table 2. Correlation Coefficient between Conductivity and Wind Velocity $(x 100)$

\begin{tabular}{lccccc}
\hline & NE & SE & SW & NW & all \\
\hline Jan & -4 & $(+43)$ & $(-27)$ & +67 & +67 \\
Feb & -12 & +15 & $(+27)$ & +65 & +60 \\
Mar & +39 & +1 & +1 & +64 & +52 \\
Apr & +44 & +8 & -13 & +72 & +30 \\
May & +31 & +4 & -5 & +57 & +5 \\
Jun & +48 & +6 & -32 & +27 & -8 \\
Jul & -8 & -26 & -39 & +38 & -27 \\
Aug & +36 & -8 & -29 & +14 & -22 \\
Sep & +30 & +9 & -21 & +33 & -5 \\
Oct & +33 & +31 & -2 & +76 & +67 \\
Nov & +2 & +44 & +39 & +74 & +69 \\
Dec & +9 & $(-34)$ & $(+88)$ & +72 & +74 \\
& & & & & \\
Year & +21 & -0 & -16 & +63 & +30 \\
\hline
\end{tabular}

( ) : occurrence frequency $<5 \%$

\section{Discussions}

The atmospheric conductivity is a measure of cleanness of air. Inverse relations of the concentration of aerosols and conductivity are commonly observed at Sakushima in every season. A very simple and easy explanation for the parallel variations of conductivity and wind velocity is as follows. The pollution source is assumed to give a steady supply of aerosols in air. The air volume passing over the source area in unit time contains a constant quantity of aerosols. Since this air volume is proportional to the wind speed, the higher wind speed makes the cleaner air stream, and thus the parallelism appears between the variations of conductivity and wind velocity. This easiest idea comes to be more complicated and the simple relation is more or less disturbed in the consideration of other realistic factors such as the mixing upwards, change in physical properties of aerosols in transport, time variation of supply of source pollution, etc. However, the idea perhaps tells a part of the truth.

For the stable occurrence of this phenomenon the locality of the station and the geographical and meteorological conditions surrounding it 


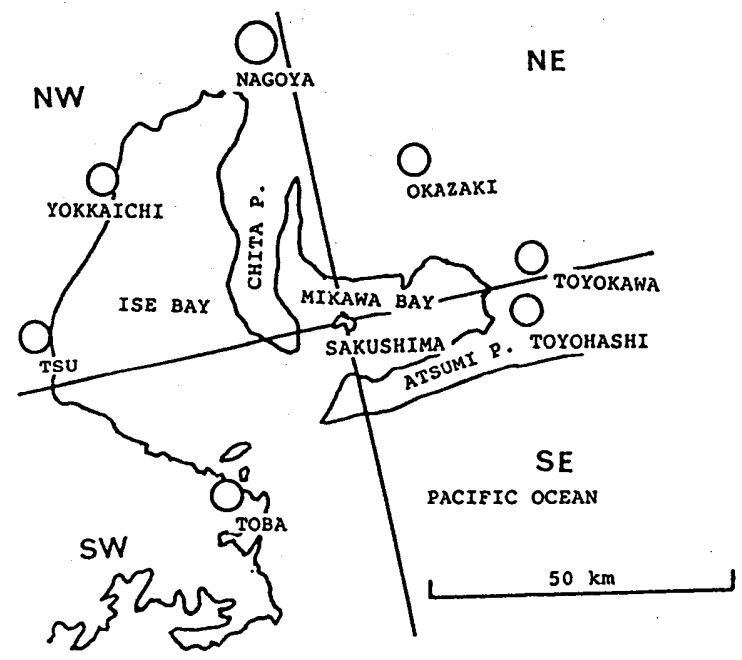

Fig. 3. Map inside about $50 \mathrm{~km}$ from the observation site.
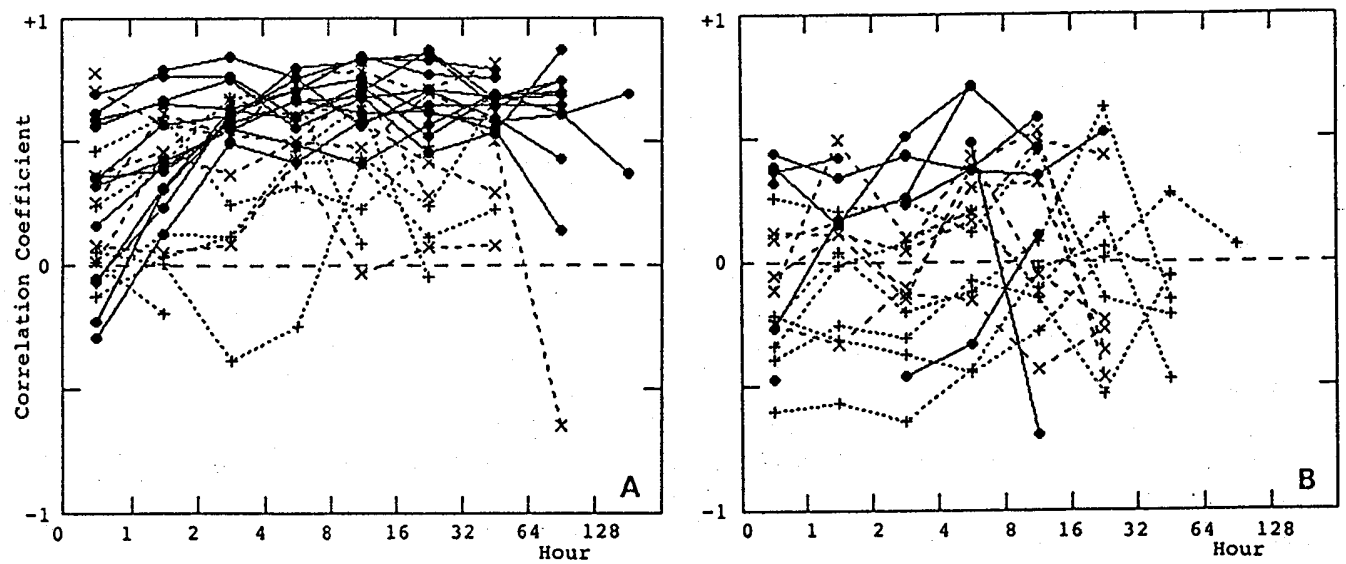

Fig. 4. Correlation coefficient vs. continuing hours of same wind direction. See text for line and mark indications.

$\mathrm{A}: \mathrm{NW}$ wind, $\mathrm{B}: \mathrm{SE}$ wind.

will be important. There is no serious production of aerosols inside the small island, Sakushima, so that the station position in the island is beside the big question. Figure 3 is a map showing circumstances within about $50 \mathrm{~km}$ circle from the station. Four sectors used above as classifying wind directions are also shown. Although we have no information which directly points out the source position of aerosols at Sakushima, the sector $\mathrm{NW}$ includes the most active industrial zone centered at Yokkaichi at the distance of $50 \mathrm{~km}$. The $\mathrm{NW}$ wind passed over this zone then crosses Chita Peninsula where the pottery is well-known.

The velocity of winter NW wind is generally 1 to $7 \mathrm{~m} / \mathrm{s}$. For the velocity of $3 \mathrm{~m} / \mathrm{s}$, the time required to travel the distance of $50 \mathrm{~km}$ is about 5 hours. The surface wind may be reduced by friction with the ground surface than the effective transport speed of aerosols, which is assumed as 
$700 \mathrm{mb}$ wind in some cases (Ogawa and Huzita, 1978). Anyway it will be necessary to cause in stable the observed relationship that the wind direction is maintained for at least a few hours. Figure $4(A)$ shows the effect of continuing hours of wind in NW direction. The ordinate is correlation coefficient and the abscissa is hours from the time when the wind has changed to NW from other directions. Each curve corresponds to a month during 2 years. Different marks are used according to the season types; winter $(--)$, summer $(\cdots+\cdots)$, and equinoxes $(--x-\rightarrow)$. It is confirmed that there is a tendency satisfying high correlations after the NW wind has continued for 3 to 4 hours. These relations are not seen at all in other wind directions. In another example, Fig. 4(B) for SE direction typical in summer, no correlation is found even after the same direction has continued more than 10 hours. This suggests that pollutions over Sakushima in summer originate from wide area and that the air loaded with long-lived and wellmixed pollutions resides for long time and produces low conductivity compared with that under strong winter wind. A high conductivity in summer was observed in connection with typhoons, which seemed to blow pollutions off toward inland by the very strong south wind from the ocean (Morita and Ishikawa, 1974). Excepting this special case, other than in winter this area is thought to be under the influence of pollution of widely distributed complex origins, which makes the effect of wind ambiguous.

\section{References}

Israel, H. , Atmospheric Electricity (English Translation), Israel Program for Scientific Translations, Jerusalem, 99, 1970.

Iwata, A., H. Ishikawa, M. Takagi, and Y. Morita, Observed results of atmospheric electrical elements at Sakushima, Proc. Soc. Atmos. Electr. Jpn. , 13, 98-102, 1975 .

Morita, Y. and H. Ishikawa, Results of ion and aerosol observation under the influence of typhoons, Proc. Soc. Atmos. Electr. Jpn. , 10, 6-9, 1974 .

Morita, Y., A. Iwata, M. Takagi, and H. Ishikawa, Properties of ions and aerosols at Sakushima in Mikawa Bay, Proc. Soc. Atmos. Electr. Jpn., 17, $41-45,1977$.

ogawa, T., Diurnal variation in atmospheric electricity, J. Geomag. Geoelectr., 12,1-12, 1960.

ogawa, T. and A. Huzita, Atmospheric electric field measurement as a monitor of large scale air-politution, J. Met. Soc. Jpn., . 57, 84-87, 1979.

(Received October 5, 1990;

Revised December 10, 1990;

Accepted December 17, 1990.) 